Available online on 15.07.2018 at http://jddtonline.info
Journal Of Drug Delivery and Therapeutics
$\begin{gathered}\text { Open Access to Pharmaceutical and Medical Research } \\ \text { 2011-18, publisher and licensee JDDT, This is an Open Access article which permits unrestricted non- } \\ \text { commercial use, provided the original work is properly cited }\end{gathered}$

Open Access

Research Article

\title{
FORMULATION AND CHARACTERIZATION OF MUCOADHESIVE MICROSPHERES OF GLICLAZIDE HYDROCHLORIDE
}

\author{
Dr. Siraj N Shaikh*, Shaikh Saad, Dr. G. J. Khan, Sharukh Y Pathan \\ Department of Pharmaceutics, Ali-Allana College of Pharmacy Akkalkuwa, Nandurbar, Maharashtra, India
}

\begin{abstract}
This article illustrates the Formulation and Characterization of Mucoadhesive microspheres of Gliclazide Hydrochloride. The mucoadhesive microspheres were prepared by the Emulsion Solvent Evaporation method by using Eudragit L 100 and Ethyl Cellulose 22 CPS polymers \& PEG 4000 added as a pore forming agent . Formulated microspheres were evaluated for various parameters. The characteristics like shape and structure of prepared microspheres were determined by Optical microscopy and scanning electron microscopy respectively. The prepared microspheres exhibited prolonged drug release (12 hrs) the mean particle size increased as the concentration of Eudragit L 100 increased. Decrease in size of microspheres leads to decrease in mucoadhesion time, \% drug loading and faster the drug release. The optimized formulation shows following cumulative release after 12 hrs i.e. $96.40 \%$. The microspheres exhibited $80 \%$ mucoadhesion and showed good drug entrapment efficiency i.e. $80.13 \pm 0.91 \%$ as well as drug loading efficiency is $26.70 \pm 0.75 \%$. It can be concluded that the present mucoadhesive microspheres can be an ideal system to deliver the Gliclazide Hydrochloride in the sustained release manner for management of Type II Diabetes Mellitus.
\end{abstract}

Keywords: Mucoadhesive, Gliclazide Hydrochloride, Microspheres, Eudragit L 100, drug entrapment efficiency.

Article Info: Received 03 March, 2018; Review Completed 30 May 2018; Accepted 03 June 2018; Available online 15 July 2018

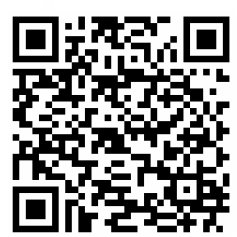

\section{Cite this article as:}

Shaikh SN, Saad S, Khan GJ, Pathan SY, Formulation and characterization of mucoadhesive microspheres of gliclazide hydrochloride, Journal of Drug Delivery and Therapeutics. 2018; 8(4):117-125 DOI: http://dx.doi.org/10.22270/jddt.v8i4.1735

*Address for Correspondence:

Dr.Shaikh Siraj N, Head Department of Pharmaceutics, Ali-Allana College of Pharmacy Akkalkuwa, Nandurbar, Maharashtra, India.

\section{INTRODUCTION $\mathbf{N}^{1,2,3}$}

Oral route of administration is much important to the conscious patient because the most of the dosage form having shot duration of action. The success of normal microspheres is limited due to short residence time at the site of absorption. The mucoadhesive microspheres would be benefited to provide a good contact of drug delivery system with absorbing membrane. They can be achieved by coupling bio-adhesion properties to microspheres and to formulating bio-adhesive microspheres.

The term microsphere is defined as a spherical particle with size from 1 um -1000um. The microsphere are typical free flowing powder consist of synthetic polymer which are Biod E.g. radable in nature and having particle size less than $200 \mathrm{um}$. The microspheres are made from highly transparent glass can perform as much high quality optical micro cavities or micro resonators. The success of these microspheres is limited having provided intimate contact of the drug delivery system with the absorbing membranes. 4

\section{MATERIALS AND METHODS}

\section{Materials:}

Gliclazide hydrochloride was obtained as gift sample from M/s Flamingo Pharmaceutical Private Limited, Nanded. Ethyl cellulose 22 CPS, Eudragit L 100, Poly Vinyl Alcohol Hot, Dichloro Methane, Methanol and Conc. Hydrochloric acid purchased from Research-Lab Fine Chemical Industries. Mumbai. The entire chemicals were of analytical grade and double distilled water used throughout the experiment.

\section{Methods:}

Formulation of Mucoadhesive Microspheres of Gliclazide 
Mucoadhesive Microsphere containing Gliclazide was prepared using Emulsion solvent evaporation method. The drug to polymer ratio used to prepare the different formulations was 1:2. The polymer content was a mixture of Eudragit L-100 and Ethyl Cellulose 22cps in varying concentration \& PEG 4000. The drug polymer mixture was dissolved in a mixture of Dichloromethane and Methanol $(1: 1 \mathrm{v} / \mathrm{v})$. The mixture was dropped in to $0.4 \%^{\mathrm{w} / \mathrm{v}}$ Polyvinyl alcohol solution $(400 \mathrm{ml})$ containing mag. stearate by 22 gauge needle. The solution was stirred with a propeller-type agitator and magnetic stirrer at $40^{\circ} \mathrm{C}$ for $1 \mathrm{~h}$ at $300 \mathrm{rpm}$. The formed mucoadhesive microspheres were filtered by whattmann filter paper washed with water and dried at $40^{\circ \mathrm{C}}$ overnight.

Table 1: Formulated batches of microspheres

\begin{tabular}{|c|c|c|c|c|c|c|}
\hline \multirow{2}{*}{$\begin{array}{l}\text { Batches } \\
\text { Codes }\end{array}$} & \multicolumn{3}{|c|}{ Drug : Polymer (1:2) } & \multirow{2}{*}{$\begin{array}{l}\text { PVA Solution } \\
(\% \text { w/v })\end{array}$} & \multirow{2}{*}{$\begin{array}{l}\text { Mag. Stearate } \\
(\% \mathrm{w} / \mathrm{v})\end{array}$} & \multirow{2}{*}{$\begin{array}{l}\text { PEG 4000 } \\
(\% \text { w/v })\end{array}$} \\
\hline & Drug (mg) & $\begin{array}{l}\text { Eudragit L100 } \\
\text { (mg) }\end{array}$ & $\begin{array}{l}\text { Ethyl Cellulose } \\
\text { 22cps (mg) }\end{array}$ & & & \\
\hline B1 & 300 & 485 & 115 & 0.4 & 0.1 & 0.5 \\
\hline B2 & 300 & 400 & 200 & 0.4 & 0.1 & 0.5 \\
\hline B3 & 300 & 300 & 300 & 0.4 & 0.1 & 0.5 \\
\hline B4 & 300 & 200 & 400 & 0.4 & 0.1 & 0.5 \\
\hline B5 & 300 & 100 & 500 & 0.4 & 0.1 & 0.5 \\
\hline B6 & 300 & 450 & 150 & 0.4 & 0.1 & 0.5 \\
\hline B7 & 300 & 500 & 100 & 0.4 & 0.1 & 0.5 \\
\hline B8 & 300 & 475 & 125 & 0.4 & 0.1 & 0.5 \\
\hline
\end{tabular}

\section{Evaluation of Microspheres}

\section{1) $\mathrm{FT}-$ IR $^{7,8}$}

FT-IR spectra for pure Gliclazide Hydrochloride and Different polymers acquired at room temperature using FT-IR spectrophotometer (FTIR-8400S, Shimadzu, Japan) in transmittance mode. The samples were ground in a mortar, mixed with Nujol and placed between two plates of $\mathrm{KBr}$ and compressed to form a thin film. The sandwiched plates were placed in the infrared spectrometer and the spectra were obtained. Scanning was performed between wave numbers $4000-400 \mathrm{~cm}^{-1}$

\section{2) Differential scanning colorimetry analysis ${ }^{9,10}$}

Method for estimating the physical interaction between drug and polymers used for the formulation of different dosage form is thermal analysis by DSC. In the present studies the DSC analysis of Gliclazide Hydrochloride hydrochloride, and ethyl cellulose with Eudragit L 100 for preparation of muco-adhesive microsphere (B1-B8) were carried out using a Shimadzu DSC 60, Japan; to evaluate any possible polymer drug thermal interaction. Exactly weighed 5 to $6 \mathrm{mg}$ samples were hermetically sealed in aluminium crucible and heated at constant rate of $10^{\circ} \mathrm{C} / \mathrm{min}$ over a temperature range of 40 to $300^{\circ} \mathrm{C}$. Inert atmosphere was maintained by purging nitrogen gas at a flow rate of $50 \mathrm{ml} / \mathrm{min}$.

\section{3) Nature of particles ${ }^{11}$}

The smooth surface of particle improves the flow. The particle having high density and low internal porosity tend to process good flow properties. Flate and elongated particle tend to pack loosely and give high porosity. The generation of electrical charge by friction between two particles during the movement also lead to cohesion.

\section{4) Percentage Practical yield ${ }^{12}$}

The percentage yield is athe percentage ratio of actual yield to theoretical yield. The measured weight was divided by total amount of all non-volatile components which were used for the preparation of microsphere. Percentage yield can be calculated using the formula,

$$
\% \text { Practical Yield }=\frac{\text { Actual Drug content }}{\text { Total weight of microspheres }} \times 100
$$

\section{5) Particle size ${ }^{13}$}

The most widely used procedures to visualize microparticles are conventional light microscopy (LM) and scanning electron microscopy (SEM). Samples of the microparticles were analyzed for particle size by optical microscope. The instrument was calibrated and found that lunit of eyepiece micrometer was equal to $12.5 \mu \mathrm{m}$. Nearly about 100 Microparticles sizes were calculated under $45 \mathrm{x}$ magnifications. The microsphere size distribution was determined by the optical microscopy method using a calibrated stage micrometer $(\mu \mathrm{m})$ and size was calculated by using equation.

$$
\mathrm{Xg}=10 \times[(\operatorname{ni} \mathrm{x} \log \mathrm{Xi}) / \mathrm{N}]
$$

$\mathrm{Xg}$ is geometric mean diameter, ni is number of particle in range, $\mathrm{xi}$ is the midpoint of range and $\mathrm{N}$ is the total number of particles. All the experimental units were analyzed in triplicate.

\section{6) Density determination ${ }^{14}$}

The density of microsphere is measured by using a multi volume psychomotor. Exact weight sample in a cup is placed into the multi volume psychomotor. The helium is come the contact pressure in the chamber and allowed expand. These expansion results are to minimize pressure within the chamber. The two successive reading of reduce pressure at different first pressure are noted. From two pressures reading the density of the microsphere carrier is determined.

\section{1) Tapped density ${ }^{15,16}$}

Accurately weighed quantity of powder is introduced into a measuring cylinder. Mechanically tap the cylinder containing the sample by raising the cylinder and 
allowing it to drop under its own weight using a suitable mechanical tapped density tester at a nominal rate of 300 drops/min. Tap the cylinder 500 times and measure the tapped volume (Va). Repeat the operation for an additional 750 tappings and again measure the tapped volume as $(\mathrm{Vb})$. If the difference between $\mathrm{Va}$ and $\mathrm{Vb}$ is $<2 \%, \mathrm{Vb}$ is the final tapped volume ( $\mathrm{Vf})$. If the difference is higher, repeat the tapings for an additional 1,250 times, and then the tapped density can be calculated using the following formula

$$
\text { Tapped Density }=\frac{\text { Mass }}{\text { Tapped Volume }} \times 100
$$

\section{2) Bulk density ${ }^{17,18}$}

The bulk density depends on particle size, shape and cohesiveness of particle. Unless otherwise specified, pass a quantity of material sufficient to complete the test through a 1.00-mm (no. 18) screen to break up agglomerates that may have formed during storage. Into a dry 250-ml cylinder introduce, without compacting, approximately $100 \mathrm{~g}$ of the test sample (M) weighed with $0.1 \%$ accuracy. If it is not possible to use $100 \mathrm{~g}$, the amount of the test sample and the volume of the cylinder may be modified. Select a sample mass having an untapped apparent volume of 150-250 ml. A 100-ml cylinder is used for apparent volumes between 50 and $100 \mathrm{ml}$. Fill the cylinder carefully. Carefully level the powder without compacting, if necessary, and read the unsettled apparent volume (Vo). Calculate the bulk density, in $\mathrm{g} / \mathrm{ml}$, using the formula,

$$
\text { Bulk Density }=\frac{\text { Mass }}{\text { Bulk Volume }} \times 100
$$

Bulk density is used to check the uniformity if bulk chemical. The size of capsule is mainly determined by bulk volume for given dose of material.

\section{7) Flow properties}

\section{1) Angle of repose $e^{19}$}

It is determined by allowing a powder to flow through a funnel and fall freely on to a surface. Further addition of powder is stopped as soon as the pile touches the tip of the funnel. A circle is drawn around the pile without disturbing it. The height and diameter of the resulting cone are measured. The same procedure is repeated three times and the average value is taken. Angle of repose is calculated by using the following equation:

$$
\theta=\operatorname{Tan}^{-1} \mathrm{~h} / \mathrm{r}
$$

Where, $\mathrm{h}=$ height of the powder cone; $\mathrm{r}=$ radius of the powder

\section{2) Hausner Ratio ${ }^{20}$}

The Hausner ratio can be determined using the following formula:

$$
\text { Hausner Ratio }=\frac{\text { Tapped Density }}{\text { Bulk Density }} \times 100
$$

\section{3) Carr's index ${ }^{21}$}

The compressibility index of granules can be determined using Carr's compressibility index, and can be determined by the following formula:

$$
\text { Carr's Index }=\frac{\text { Tapped Density }}{\text { Bulk Density }} \times 100
$$

\section{8) Drug entrapment efficiency ${ }^{22}$}

The microspheres containing drug were compressed and then dissolve in small amount of methanol \& then in distilled water with the help of ultrasonic stirrer for three hours. Than it filtered and assay by ultra violet radiation spectroscopy. The entrapment of efficiency is equal to ratio of real drug content to theoretical drug content.

$$
\% \mathrm{DEE}=\frac{\text { Practical Drug Content }}{\text { Therotical Drug Content }} \times 100
$$

\section{9) Drug loading efficiency ${ }^{23}$}

The entrapment efficiency refers actually to the capability of the drug to be entrapped while the loading capacity is actually the ability of the material to entrap a certain active substance Loading= (weight of drug in nanoparticles*100)/weight of microspheres that are obtained after the manufacture procedure. A loading dose is an initial higher dose of a drug that may be given at the beginning of a course of treatment before dropping down to a lower maintenance dose. A loading dose is most useful for drugs that are eliminated from the body relatively slowly, i.e. have a long systemic half-life.

$$
\% \text { DLE }=\frac{\text { Practical Drug Content }}{\text { Total weight of microspheres }} \times 100
$$

\section{0) In-vitro mucoadhesive study ${ }^{24}$}

Take a $2 \mathrm{~cm}$ wide and $2 \mathrm{~cm}$ long $(2 \times 2)$ piece of sheep intestinal mucosa was tied onto a glass slide using thread. About 50mg microspheres were spread onto the wet, rinsed, tissue specimen, and allowed to hydrate for $5 \mathrm{~min}$. The prepared slide was hung onto one of the grooves of a USP tablet disintegrating test apparatus. The disintegrating test apparatus was operated such that the tissue specimen was given regular up and down movements in the test fluid $(900 \mathrm{ml})$ at $37^{\circ} \mathrm{C}$ contained in one liter vessel of the machine. At the end of $1 \mathrm{~h}$, the machine was stopped and the number of microspheres still adhering to the tissue was counted. The test was performed at gastric $\mathrm{pH} 0.1 \mathrm{~N} \mathrm{HCl}$.

$$
\% \text { Mucoadhesion }=\frac{\text { microphere retaine }}{\text { Total weight of microspheres }} \times 100
$$

\section{1) Scanning electron microscopy ${ }^{25}$}

Shape and surface characteristic of hollow microspheres examine by Scanning Electronic Microscopy analysis as shown in Fig. no. 10 and 11. Surface morphology of B7 formulation examine at to different magnification $40 \mathrm{X}$ and 200X, which illustrate the smooth surface of mucoadhesive microspheres and small hollow cavity present in microsphere which is responsible for mucoadhesive property.

\section{2) In vitro drug release $e^{26,27}$}

In vitro drug release study was carried out in USP XXI paddle type dissolution test apparatus using acidic buffer pH 1.2 as dissolution medium, volume of dissolution medium was $900 \mathrm{ml}$ and bath temperature was 
maintained at $(37 \pm 1)^{\circ} \mathrm{C}$ throughout the study. Release studies for different type of microspheres are carried out by using different suitable dissolution media, mostly by rotating paddle apparatus. Paddle speed was adjusted to $50 \mathrm{rpm}$. An interval of 1 hour, one $\mathrm{ml}$ of sample was withdrawn with replacement of one $\mathrm{ml}$ fresh medium. All the experimental units were analyzed in triplicate by UV.

\section{3) Stability study ${ }^{28,29}$}

The placing of microspheres in screw capped glass container and stored them at $40^{\circ} \mathrm{c}$ and $75 \% \mathrm{Rh}$. The stability study carried out in 3 month and drug content was analyzed.

\section{RESULTS AND DISSCUSSION}

1) FT-IR

FT-IR Spectra were obtained for Gliclazide, physical mixture of and physical mixture of Gliclazide as shown in fig. no.1,5, the characteristic peaks of the Gliclazide were compared with the peaks obtained for physical mixture of Gliclazide and polymer.

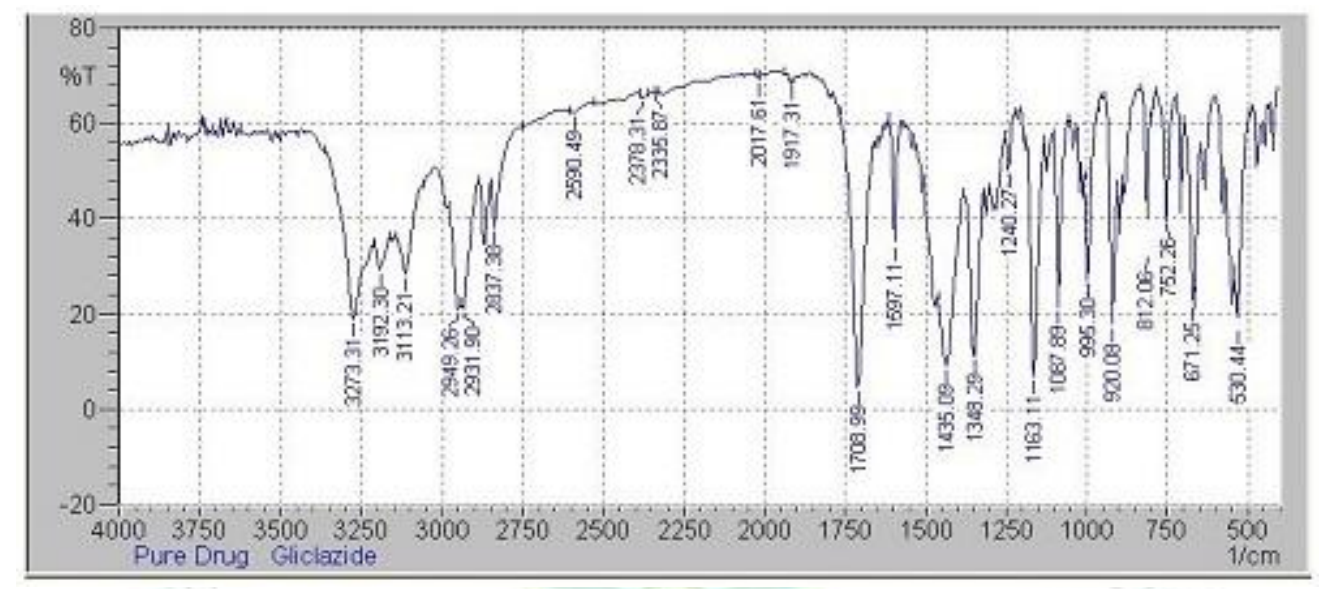

Figure 1: FT-IR Spectra of Pure Gliclazide

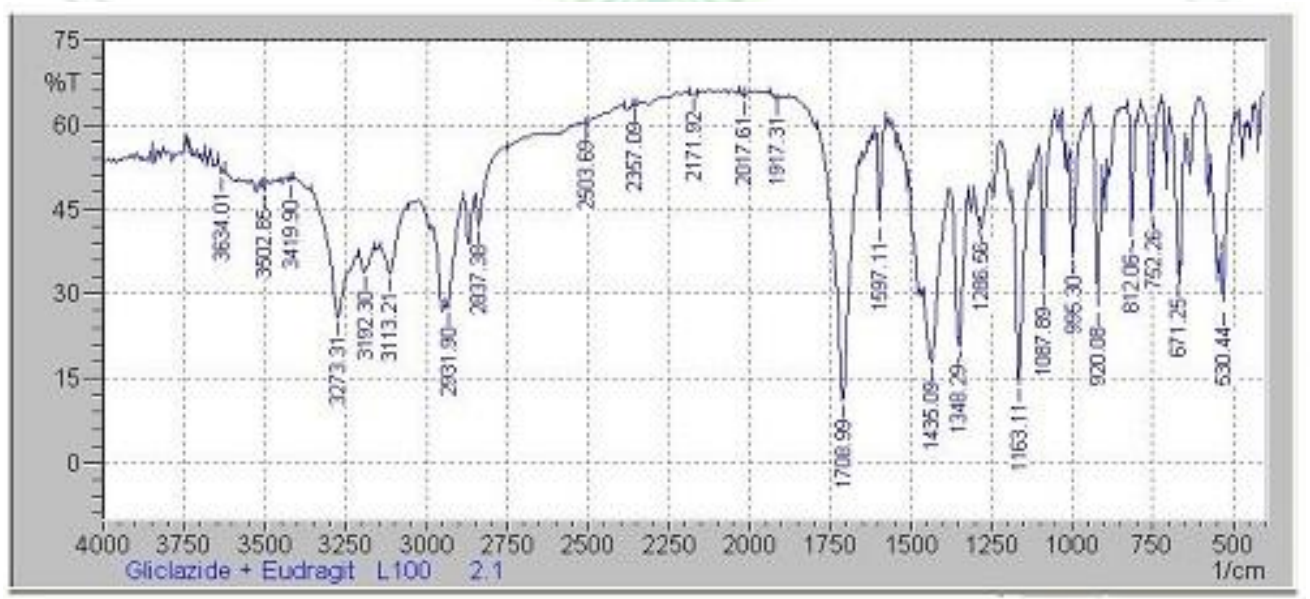

Figure 2: FT-IR Spectra of Gliclazide \& Eudragit L100

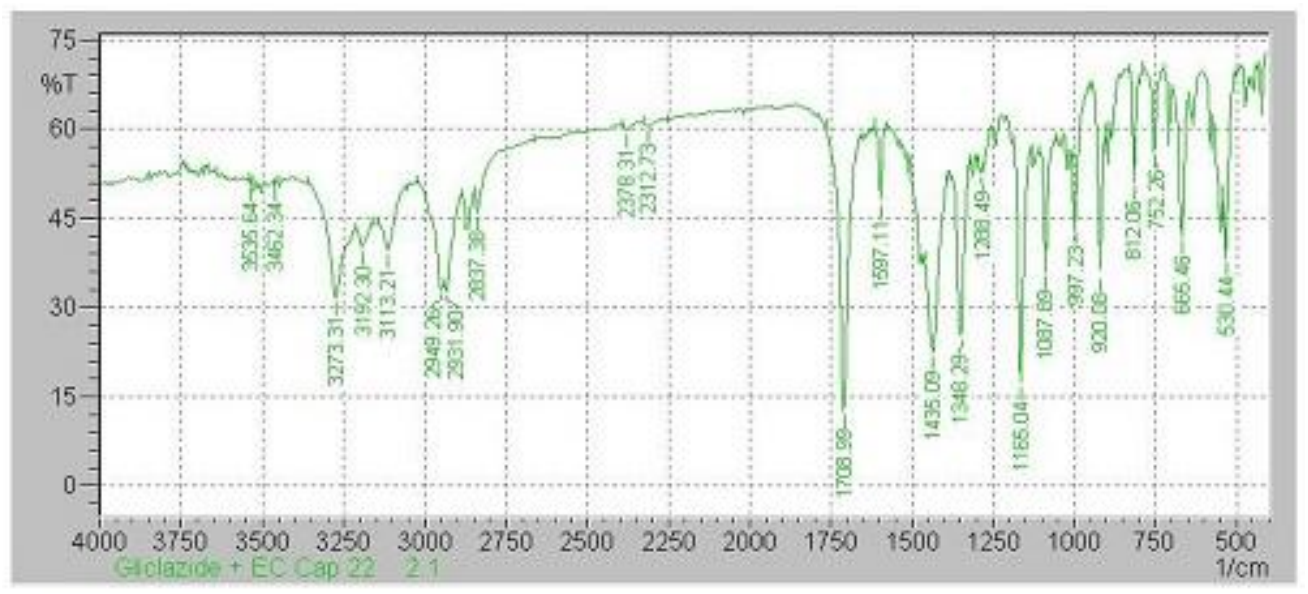

Figure 3: FT-IR Spectra of Gliclazide \& Ethyl Cellulose 


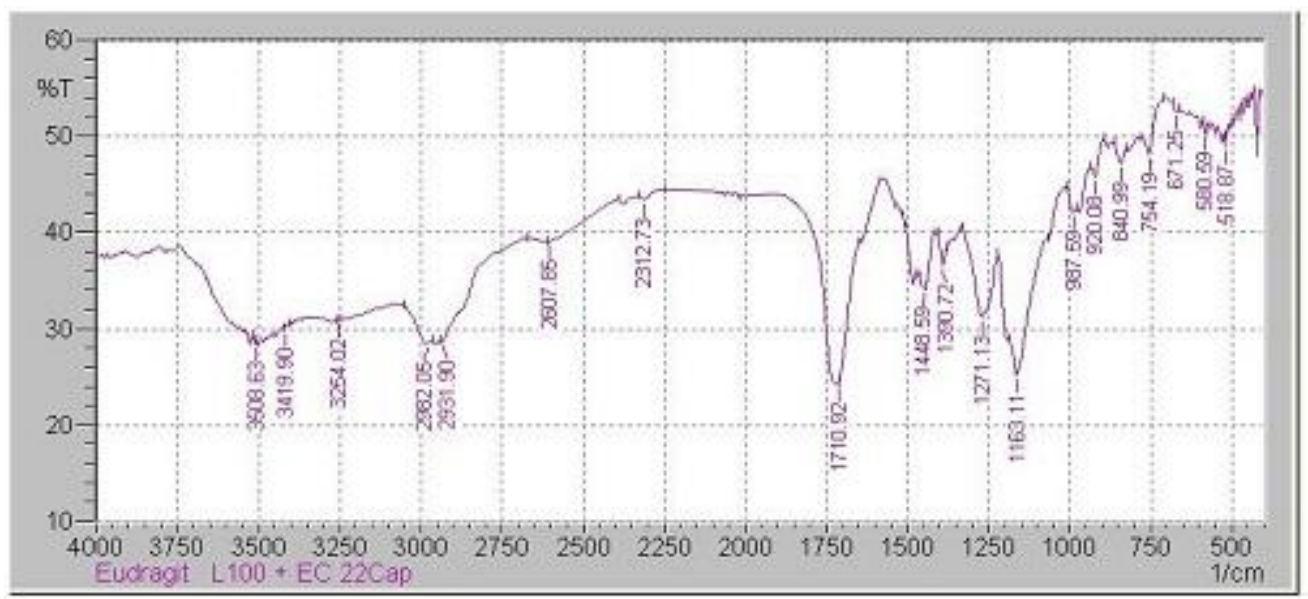

Figure 4: FT-IR Spectra of Eudragit L100 \& Ethyl Cellulose

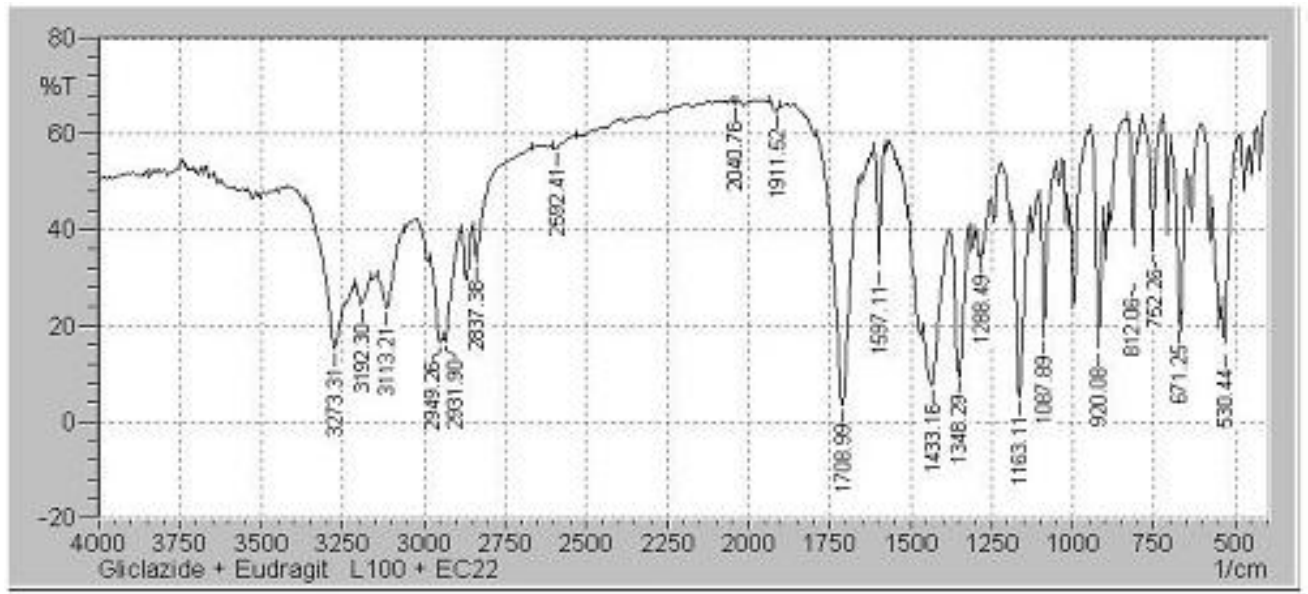

Figure 5: FT-IR Spectra of Gliclazide, Eudragit L100 \& Ethyl Cellulose

FT-IR obtained for pure Gliclazide, Gliclazide-Eudragit RS100, Gliclazide-Ethyl Cellulose and GliclazideEudragit L100 \& Ethyl Cellulose there was no chemical interaction between Gliclazide and polymer and it can be concluded that the characteristics bands of Gliclazide were not affected after successful loading.

2) Differential Scanning Colorimetric

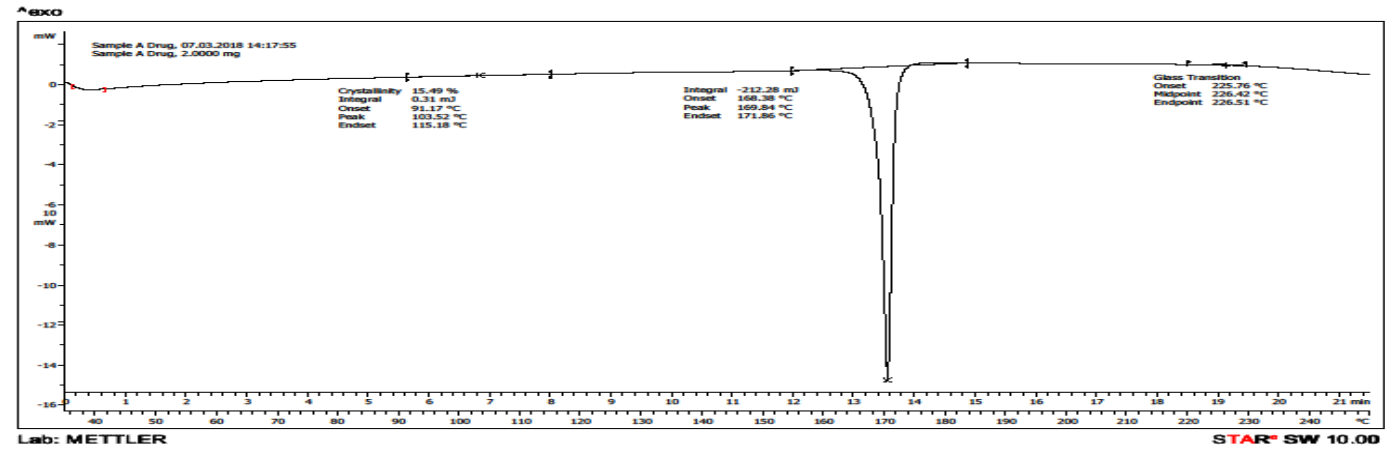

Figure 6: DSC of Pure Drug Gliclazide

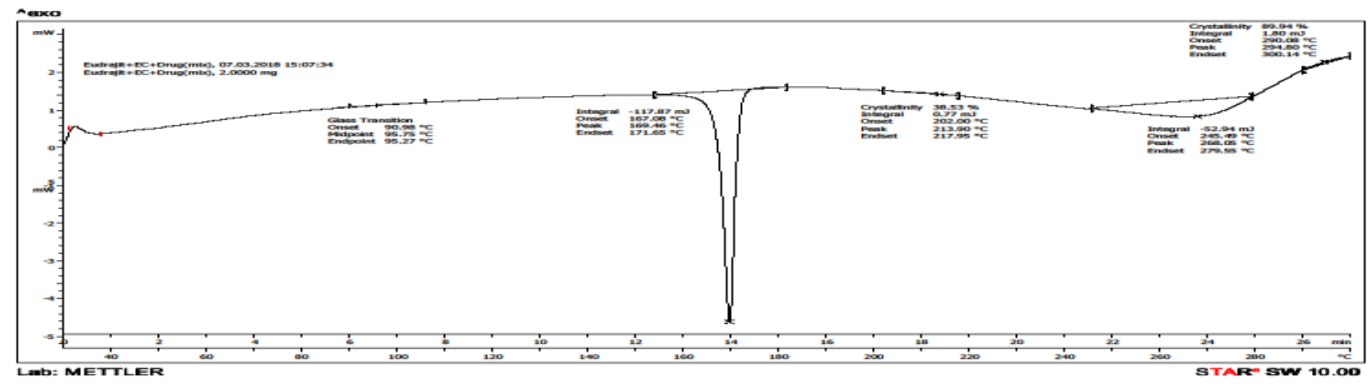

Figure 7: DSC of drug and polymers mixture 
The DSC obtained for there was no interaction between the Gliclazide and the polymer in the solid state. The melting point range of Gliclazide is between $167-207^{\circ} \mathrm{C}$, thus indicating there is no change of Gliclazide in pure state, physical mixture of drug and polymer.

\section{3) Particle size analysis}

Particle size was determined by optical microscopy method. It plays an important role in mucoadhesive ability and release of drug from microspheres. If size of microspheres is less then release rate of drug will be high and mucoadhesive ability will reduce, white microspheres size is more, then mucoadhesive ability will be more and release rate will be in sustained manner. The mean particle size of hollow microsphere was in range $214.56 \pm 0.58$ to $463.92 \pm 0.06 \mu \mathrm{m}$ as shown in table 2.

\section{4) Determination of \% practical yield of main batch}

Percentage yield of different formulation was determined by weighing the microballoons after drying. The percentage yield of different formulation was in range of $65-85 \%$ as shown in table 3
Table 2: Particle size of batch B1-B8

\begin{tabular}{|l|l|}
\hline Batch & Size $(\boldsymbol{\mu m})$ \\
\hline B1 & $371.25 \pm 0.61$ \\
\hline B2 & $390.00 \pm 0.01$ \\
\hline B3 & $369.29 \pm 0.99$ \\
\hline B4 & $214.56 \pm 0.58$ \\
\hline B5 & $295.46 \pm 0.02$ \\
\hline B6 & $402.36 \pm 0.01$ \\
\hline B7 & $463.92 \pm 0.06$ \\
\hline B8 & $435.09 \pm 0.025$ \\
\hline
\end{tabular}

Table 3: \% Practical yield B1-B8

\begin{tabular}{|l|l|}
\hline Batch & \%Practical Yield \\
\hline B1 & 80.33 \\
\hline B2 & 82.00 \\
\hline B3 & 79.11 \\
\hline B4 & 67.77 \\
\hline B5 & 65.00 \\
\hline B6 & 83.33 \\
\hline B7 & 85.00 \\
\hline B8 & 84.22 \\
\hline
\end{tabular}

\section{5) Density calculation}

Table 4: Density of batch B1-B8 microspheres

\begin{tabular}{|l|l|l|l|l|l|l|}
\hline Batches & $\begin{array}{l}\text { Bulk density } \\
\left(\mathbf{g} / \mathbf{c m}^{\mathbf{3}}\right)\end{array}$ & $\begin{array}{l}\text { Tapped density } \\
\left(\mathbf{g} / \mathbf{c m}^{\mathbf{3}} \mathbf{)}\right.\end{array}$ & $\begin{array}{l}\text { Hausner's } \\
\text { ratio }\end{array}$ & Result & $\begin{array}{l}\text { \% Carr's } \\
\text { Index }\end{array}$ & Result \\
\hline B1 & $0.0794 \pm 0.002$ & $0.0881 \pm 0.002$ & $1.10 \pm 0.10$ & Excellent & $09.87 \pm 0.18$ & Excellent \\
\hline B2 & $0.0785 \pm 0.000$ & $0.0911 \pm 0.001$ & $1.16 \pm 0.02$ & Good & $13.83 \pm 0.35$ & Good \\
\hline B3 & $0.0827 \pm 0.002$ & $0.0975 \pm 0.002$ & $1.17 \pm 0.02$ & Good & $15.17 \pm 0.10$ & Good \\
\hline B4 & $0.0847 \pm 0.000$ & $0.0983 \pm 0.001$ & $1.16 \pm 0.02$ & Poor & $13.83 \pm 0.20$ & Good \\
\hline B5 & $0.0835 \pm 0.001$ & $0.0943 \pm 0.001$ & $1.12 \pm 0.02$ & Fair & $11.45 \pm 0.22$ & Good \\
\hline B6 & $0.0797 \pm 0.000$ & $0.0872 \pm 0.001$ & $1.09 \pm 0.02$ & Excellent & $08.60 \pm 0.37$ & Excellent \\
\hline B7 & $0.0780 \pm 0.001$ & $0.0840 \pm 0.001$ & $1.07 \pm 0.02$ & Excellent & $07.14 \pm 0.06$ & Excellent \\
\hline B8 & $0.0797 \pm 0.001$ & $0.0871 \pm 0.001$ & $1.09 \pm 0.02$ & Excellent & $08.49 \pm 0.09$ & Excellent \\
\hline
\end{tabular}

6) Angle of repose

Table 5: Angle of repose of B1-B8

\begin{tabular}{|l|l|l|}
\hline Batches & Angle of repose & Result \\
\hline B1 & $27.02 \pm 0.98$ & Excellent \\
\hline B2 & $28.81 \pm 0.85$ & Excellent \\
\hline B3 & $33.82 \pm 1.14$ & Good \\
\hline B4 & $33.02 \pm 1.01$ & Good \\
\hline B5 & $29.24 \pm 1.24$ & Excellent \\
\hline B6 & $27.92 \pm 1.02$ & Excellent \\
\hline B7 & $27.47 \pm 0.77$ & Excellent \\
\hline B8 & $29.24 \pm 0.55$ & Excellent \\
\hline
\end{tabular}

\section{7) Drug entrapment efficiency}

The drug entrapment efficacies of different formulations were in range of $62.84 \pm 0.82$ to $80.13 \pm 0.91 \%$ w/w as shown in following table. Drug entrapment efficacy slightly decrease with increase Ethyl cellulose content and decreased Eudragit L100 ratio in microspheres.
Table 6: \%DEE of batch B1-B8

\begin{tabular}{|l|l|}
\hline Batch & \%DEE \\
\hline B1 & $72.14 \pm 0.02$ \\
\hline B2 & $70.82 \pm 0.19$ \\
\hline B3 & $66.92 \pm 1.94$ \\
\hline B4 & $65.54 \pm 0.42$ \\
\hline B5 & $62.84 \pm 0.82$ \\
\hline B6 & $75.33 \pm 0.91$ \\
\hline B7 & $80.13 \pm 0.91$ \\
\hline B8 & $78.75 \pm 0.55$ \\
\hline
\end{tabular}

\section{8) Drug Loading efficiency}

The drug loading efficiencies of microspheres were in the range of $21.84 \pm 0.74$ to $26.70 \pm 75 \% \mathrm{w} / \mathrm{w}$ as shown in following table: 
Table 7: \%DLE of batch B1-B8

\begin{tabular}{|l|l|}
\hline Batch & \%DLE \\
\hline B1 & $24.04 \pm 0.94$ \\
\hline B2 & $23.60 \pm 0.86$ \\
\hline B3 & $22.30 \pm 0.20$ \\
\hline B4 & $21.84 \pm 0.74$ \\
\hline B5 & $20.94 \pm 0.99$ \\
\hline B6 & $25.10 \pm 1.03$ \\
\hline B7 & $26.70 \pm 0.75$ \\
\hline B8 & $26.24 \pm 0.97$ \\
\hline
\end{tabular}

\section{9) Percentage Mucoadhesive test}

The ability of mucoadhesion of different formulation were found to be differed according to Eudragit L100 and Ethyl cellulose ratio. B1, B6, B7 \& B8 formulations showed best mucoadhesive ability in 1 hours. B2, B3, B4 \&B5 formulation showed less mucoadhesive ability as showed in following table. The mucoadhesive ability of microsphere is decreased by increasing the Ethyl cellulose ratio.

Table 8: \% Mucoadhesion test of B1-B8

\begin{tabular}{|l|l|}
\hline Batches & \% Mucoadhesion after 1 Hrs \\
\hline B1 & $70 \pm 1.37$ \\
\hline B2 & $56 \pm 1.00$ \\
\hline B3 & $50 \pm 2.64$ \\
\hline B4 & $46 \pm 3.00$ \\
\hline B5 & $44 \pm 2.00$ \\
\hline B6 & $74 \pm 2.64$ \\
\hline B7 & $80 \pm 2.64$ \\
\hline B8 & $80 \pm 1.73$ \\
\hline
\end{tabular}

\section{0) Scanning electron microscopy}

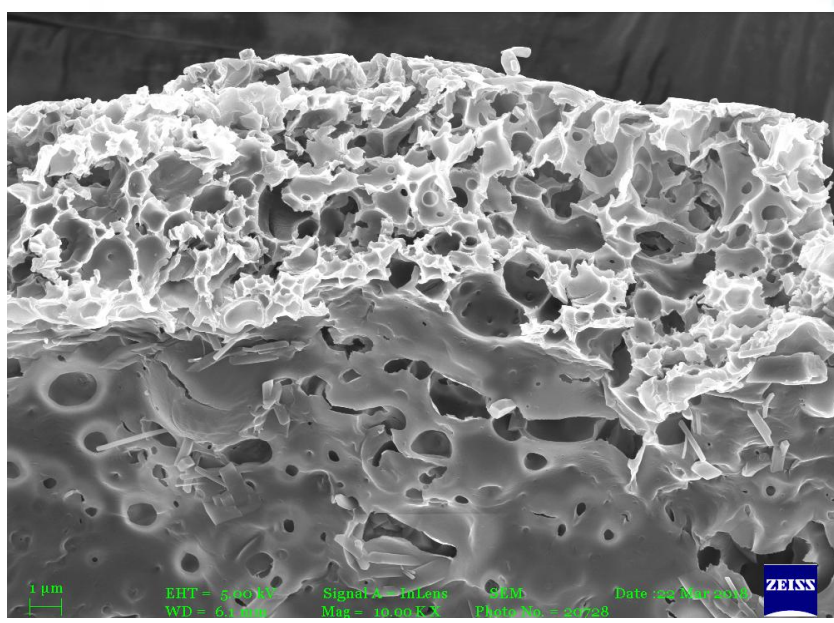

Figure 8: SEM of B7

\section{1) In-vitro drug release}

The In-vitro drug release was performed using paddle type dissolution apparatus. In this method, a weighed quantity of the microsphere which is equal to dose is placed in muslin cloth and tie to the paddle. The dissolution study performed using 900ml $0.1 \mathrm{~N} \mathrm{HCl}(\mathrm{pH}$ 1.2) for $12 \mathrm{Hrs}$ at $37 \pm 0.5{ }^{\circ} \mathrm{C}$ stirred 50rpm. The mucoadhesive microspheres release the drug 86.65 to $96.40 \%$ from batch B1 -B8 \& PEG400 also affects in vitro drug release.

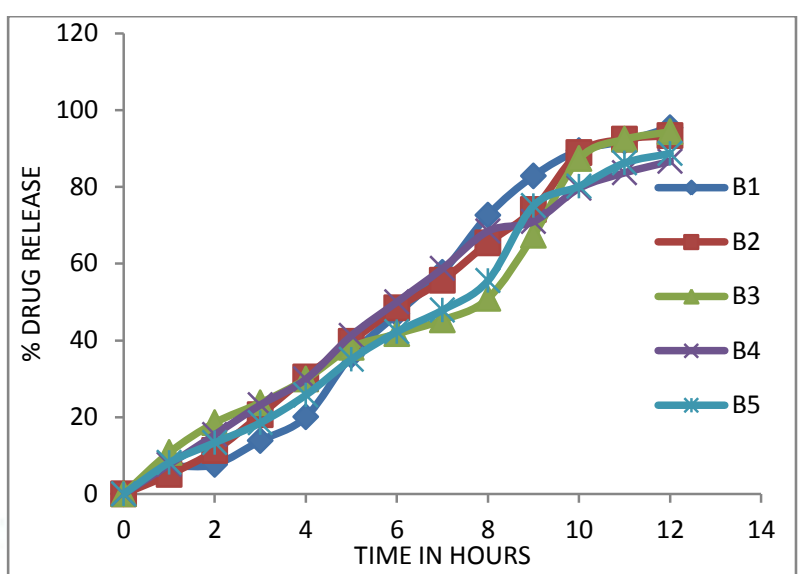

Figure 9: \%DR of B1, B2, B3, B4 \& B5

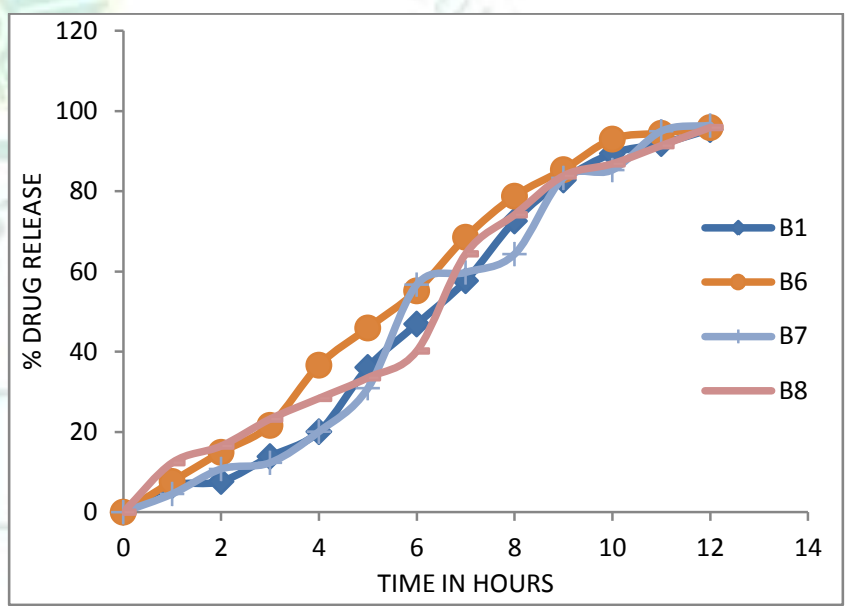

Figure 10: \%DR of B1, B6, B7 \& B8

The in vitro performance of Gliclazide mucoadhesive microspheres showed sustained release of Gliclazide. The results of the In-vitro dissolution studies show as Ethyl Cellulose 22cps concentration increases the drug release from the mucoadhesive microsphere decreases. In-vitro drug release was found in the range of $86.65 \%$ to $96.40 \%$ over the $12 \mathrm{hrs}$.

12) Release kinetic

Table 9: Release kinetic of B7

\begin{tabular}{|l|l|l|l|l|l|l|}
\hline \multirow{2}{*}{ Formulation code } & Higuchi & Zero Order & First Order & Hixoncrowell & \multicolumn{2}{|l|}{ Korsemeyer-Peppas } \\
\cline { 2 - 7 } & $\mathbf{r}^{\mathbf{2}}$ & $\mathbf{r}^{\mathbf{2}}$ & $\mathbf{r}^{\mathbf{2}}$ & $\mathbf{r}^{\mathbf{2}}$ & $\mathbf{r}^{\mathbf{2}}$ & $\mathbf{N}$ \\
\hline B7 & 0.94 & 0.96 & 0.88 & 0.93 & 0.93 & 1.33 \\
\hline
\end{tabular}


Drug release pattern was evaluated in $0.1 \mathrm{~N} \mathrm{HCl}$ of $\mathrm{B} 7$ formulation. Kinetics and mechanism of drug release from B7 formulation was evaluated on the basis of Higuchi equation, Zero order, First order, Hixon-crowell equation and Peppas model. Correlation coefficient (r2) and slope value for each equation in the range of ( $\mathrm{r} 2=$ 0.83 to 0.984 and $n=0.11-42.92$ ) was calculated.
The diffusion exponent ' $n$ ' values of KorsemeyerPeppas model was found to be in the range of 1.33 for the Gliclazide mucoadhesive microspheres prepared with Eudragit L100 and EC22cps indicating Super Case II transport of drug through Gliclazide mucoadhesive microspheres.

\section{3) Stability study}

Table 10: Results of stability study of B7

\begin{tabular}{|l|l|l|l|}
\hline Sr. no. & Parameters evaluated & Before stability & After stability \\
\hline 01. & \%DEE & $80.13 \pm 0.91$ & $78.14 \pm 0.12$ \\
\hline 02. & \%DR & 96.40 & 91.59 \\
\hline
\end{tabular}

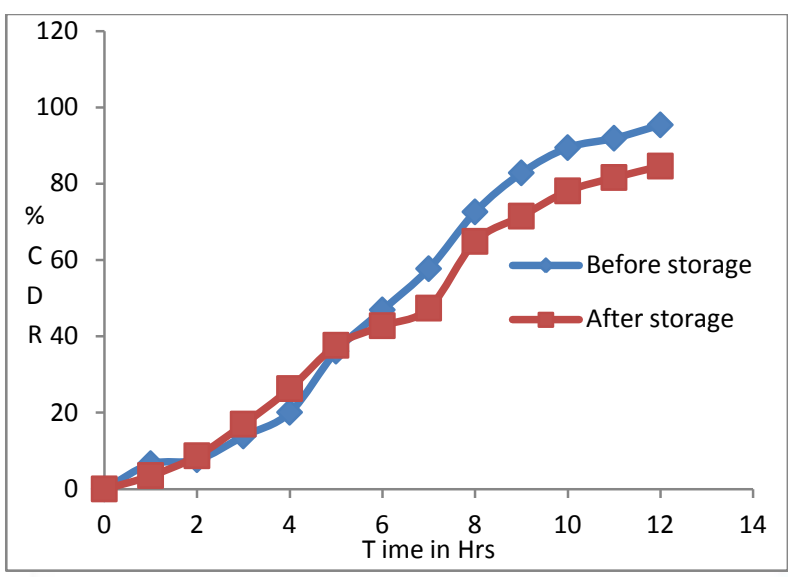

Figure 16: Comparison of \%DR of $B 7$ before \&after stability study

\section{* Stability studies}

The stability study of B7 batch was performed at $40^{\circ \mathrm{C}}$ and $95.38 \% \mathrm{Rh}$ for 3 months. After performing the dissolution of B7 batch after 3 months the percentage drug release was found to be $91.59 \%$. It has been observe that there is no significant difference in percentage drug release and \%DEE after stability study.

\section{CONCLUSION}

By studying all the experimental results it was conclusively demonstrated that Gliclazide Hydrochloride Mucoahesive microspheres loaded with

\section{REFERENCES}

1) Sirisha VNL, Chinna Eswariah M, Sambasiva Rao A. A Novel Approach of Locust Bean Gum Microspheres for Colonic Delivery of Mesalamine: Research Article. International Journal of Applied Pharmaceutics. 2018; (10):86-93.

2) Hu X, Zhang J, Tang X, Li M, Ma S, Liu C, Gao Y, Zhang Y et al. An Accelerated Release Method of Risperidone Loaded PLGA Microspheres with Good IVIVC: Research Article. Current Drug Delivery. 2018; (15):87-96.

3) Kumar S, Anusha G, Rajyalaxmi, Srinivas and Manoj. Design and Evaluation of A Controlled Release Drug Delivery System For Management of Rheumatism: Research Article. Journal of Pharmacovigilance. 2017; (5):6-17.

4) Verma V, Patel MM. Formulation and Evaluation of Mucoadhesive Microspheres Of Antihypertensive Drug, World Journal of Pharmacy and Pharmaceutical Sciences, 2017; (6):929-950. macromolecular Mucoahesive polymers can be successfully formulated by emulsification solvent evaporation method. Among eight formulations, four formulations were found to be spherical and free flowing. The ratio of Eudragit L 100 and Ethyl Cellulose 22CPS at $1: 2$ and $1: 1$, were found to be optimum for the formulation of mucoadhesive microsphere. B1, B6 and B8 possessed the best results among all the formulations in terms of surface smoothness and shape. Therefore, Eudragit L 100 and Ethyl Cellulose 22CPS can be considered as promising materials for designing Gliclazide Hydrochloride mucoadhesive microspheres. The best cumulative release was achieved after 12 hrs i.e. $96.40 \%$. PEG400 also affects in vitro drug release. The microspheres exhibited $80 \%$ mucoadhesion and showed good drug entrapment efficiency i.e. $80.13 \pm 0.91 \%$ as well as drug loading efficiency is $26.70 \pm 0.75 \%$.

It can be concluded that the present mucoadhesive microspheres can be an ideal system to deliver the Gliclazide Hydrochloride in the sustained release manner for management of Type II Diabetes Mellitus.

\section{ACKNOWLEDGEMENT}

The authors are thankful to Hazrat Maulana G.M. Vastanvisahab, President and Akbar Patel Sir Coordinater of Jamia Islamia Ishaatul Uloom's Ali Allana College of Pharmacy Akkalkuwa Dist. Nandurbar for providing the work facilities
5) Kumar S, Nanda A. Formulation Optimization and In-Vitro Evaluation of Gastroretentive Mucoadhesive Microspheres of Furosemide: Research Article. International Journal of Pharmacy and Pharmaceutical Sciences. 2016; (8):392-398.

6) Shanthi Priya CH. Design and Characterization of Mucoadhesive Microspheres for Gastro-Retentive Delivery of Famotidine Hydrochloride: Research Article. Bioengineering \& Biomedical Science. 2015; (5):1-6.

7) Gada S, Yeganoor AK. Formulation and Evaluation of Glipizide Mucoadhesive Microspheres: International Journal of Pharma Research and Health Sciences. December 2016; (4):1483-1488.

8) Agarwal D, Ranawat M, Chauhan C, Kamble R. Formulation and charecterisation of colon targeted ph dependent microspheres of capecitabine for colorectal cancer. Journal of 
Drug Delivery and Therapeutics, 2014; 3(6):215-222 . doi:10.22270/jddt.v3i6.747

9) Shaikh S, Khan G J, Shaikh S, Fakir H, Shaikh S And Shaikh M F. Microspheres As A Multiparticulate Drug Delivery System: A Review. World Journal of Pharmacy and Pharmaceutical Sciences. 2016; (5):274-292.

10) Shaikh TA, Shinkar DM, Saudagar RB, Review: Polymers Used in the Mucoadhesive Drug Delivery System, International Journal of Pharma Research \& Review, May 2016; 5(5):45-53

11) Sivasankar Mohanty And Gottumukkala Krishna Mohan. Formulation And In-Vitro Evaluation Of Glipizide Loaded Microspheres Prepared With Pectin Extracted From Dillenia Indica \& Abelmoschus Esculentus, Research Article. International Journal of Pharma and Bio Sciences. July 2015; (6):498-505.

12) Reddy DV, Navaneetha K. Comparative Assessment of Potential of Various Polymers in the Formulation Development and Evaluation of Mucoadhesive Microspheres of Glipizide: Research Article. Journal of Global Trends in Pharmaceutical Sciences. 2015; (6):2379-2387.

13) Rouf MA Mamun A, Bagchi M, Amin ML, Sutradhar BK, Huda NH. Development Of Natural Gum Based Glipizide Mucoadhesive Microsphere: Research Article. Journal of Applied Pharmaceutical Science. Jan 2014; (4):066-069.
14) Sharma HK, Lahkar S, Nath LK. Formulation And In Vitro Evaluation Of Metformin Hydrochloride Loaded Microspheres Prepared With Polysaccharide Extracted From Natural Sources: Research Article. Acta Pharm, January 2013: (63):209-222.

15) Sarfaraz Md, Venubabu.P, Doddayya Hiremath and Prakash SG. Mucoadhesive Dosage Form of Glibenclamide. Design And Characterisation: Research Article. Ijpbs. Apr-Jun 2012; (2): 162-172.

16) Shailendrasingh V, Thakur A, Mazahar Farooqui B and S D Naikwade. Thermodynamic Studies Of Transition Metal Complexes With Metformin Hydrochloride Drug In $20 \%$ (V/V) Ethanol-Water Mixture: Research Article, Pelagia Research Library. 2012; (3):1406-1409.

17) Senthil A, Raja BD, Sureshkumar P, Thakkar HR, Sivakumar T. Chitosan Loaded Mucoadhesive Microspheres Of Glipizide For Treatment Of Type 2 Diabetes Mellitus In Vitro And In Vivo Evaluation: Research Article. Scholars Research Library. 2011; (3):366-379.

18) Hardenia SS, Jain A, Patel R, Kaushal A. Formulation and Evaluation Of Mucoadhesive Microspheres Of Ciprofloxacin: Research Article. Journal of Advanced Pharmacy Education \& Research. 2011; (4):214-224. 